\title{
FILOSOFIA E EPISTEMOLOGIA DA GEOGRAFIA: GRUPO DE TRABALHO EM DISCUSSÃO (ENANPEGE 2015)
}

\author{
Philosophy and epistemology of geography: \\ working group on debate (Enanpege 2015) \\ Philosophie et épistémologie de la géographie: \\ la discussion du groupe de travail (Enanpege 2015)
}

\section{Antonio Bernardes}

Doutorado em Geografia pela Universidade Estadual de São Paulo "Júlio de Mesquita Filho"(UNESP), Presidente Prudente-SP. Docente no Programa de Pós-Graduação em Geografia da Universidade Federal Fluminense (UFF). Rua José do Patrocínio, 71, sala 103 H, Centro, Campos dos GoytacazesRJ, CEP 28010-385.

E-mail:antoniobernardes@id.uff.br

\section{Dante Flávio da Costa Reis Junior}

Doutorado em Geografia pela Universidade Estadual de Campinas. Docente no Programa de PósGraduação em Geografia da Universidade de Brasilia (UnB). UnB, Depto. de Geografia, ICC-Norte (mezanino), Campus Darcy Ribeiro, 70910-900, Brasília-DF.

E-mail:dantereis@unb.br

\section{Rodrigo Dutra Gomes}

Doutorado em Geografia pela Universidade Estadual de Campinas. Docente do Programa de Pós-graduação em Geografia da Universidade Federal de Pernambuco. Universidade Federal de Pernambuco/CFCH/DCG - Avenida Acadêmico Hélio Ramos, s/n - Cidade Universitária, CEP: 50.740530, Caixa Postal 7803 - Recife-PE.

E-mail:rdutragomes@gmail.com

\section{RESUMO}

Este artigo é uma síntese das discussões que se deram na mais recente reunião de pesquisadores e pós-graduandos brasileiros na área de Filosofia e Epistemologia da Geografia, durante a realização do ENANPEGE 2015. O texto está dividido em três partes: panorama dos estudos pautados na história do pensamento geográfico; diagnóstico sobre o estado atual das pesquisas que tratam das influências filosóficas na Geografia; e, comentário sobre os trabalhos que, tendo sido comunicados nesta última edição do Encontro, demonstraram um particular interesse pelo viés teórico-metodológico.

Palavras-chave: filosofia e ciência; estudos epistemológicos; comunidade de geógrafos brasileiros. 


\section{ABSTRACT}

This article is a summary of the discussions that took place in the most recent meeting of Brazilian researchers and postgraduate students in the field of Philosophy and Epistemology of Geography, during the ENANPEGE 2015. The text is divided into three parts: an overview of the studies in history of geographical thought; an assessment of the current state of philosophical research in Geography; and a comment on the works that showed a particular interest in theoretical and methodological issues.

Keywords: philosophy and science; epistemological studies; community of Brazilian geographers.

\section{RÉSUMÉ}

Cet article fait un esquisse des discussions qui ont eu lieu dans la plus récente réunion de chercheurs et étudiants de troisième cycle dans le domaine de la Philosophie et de l'Épistémologie de la Géographie, au cours de l'ENANPEGE 2015. Le texte est divisé en trois parties: un aperçu des études dans l'histoire de la pensée géographique; une évaluation de l'état actuel de la recherche philosophique en Géographie; et un commentaire sur les travaux qui ont montré un intérêt particulier pour les questions théoriques et méthodologiques.

Mots-clés: philosophie et science; études épistémologiques; communauté des géographes brésiliens.

\section{INTRODUÇÃO}

Os debates, organizados sob a forma de Grupo de trabalho (GT), acerca dos referenciais teórico-metodológicos, da epistemologia, da história do pensamento geográfico e as influências filosóficas na Geografia, se fizeram presentes em quase todas as edições do ENANPEGE (Encontro Nacional da Associação Nacional de Pesquisa e Pós-graduação em Geografia). Em algumas delas, integraram um mesmo GT; em outras, essas diferentes "ramificações" do estudo teórico da disciplina geraram GTs específicos. O GT "Filosofia e Epistemologia da Geografia”, em especial, é uma insígnia que tem perdurado desde o VIII ENANPEGE, realizado em Curitiba no ano de 2009.

Na mais recente edição do Encontro, ocorrida entre os dias 09 e 12 de outubro de 2015, na cidade de Presidente Prudente, Estado de São Paulo, o GT "Filosofia e Epistemologia da Geografia” propôs o desenvolvimento de discussões teórico-metodológicas acerca das múltiplas e recíprocas relações entre a Geografia, a Filosofia e as Ciências - sem, contudo, segregar outros modos de conhecimento (por exemplo, o artístico e o de senso comum): relações que fundam e fundamentam distintas perspectivas de abordagem da 
realidade; paradigmas, teorias, categorias e conceitos. Buscou-se contemplar os debates epistemológicos, ontológicos, gnosiológicos, metodológicos; e, os procedimentos técnicos de pesquisas atinentes tanto à Geografia de corte social-humanista, quanto à Geografia físico-ambiental.

O GT trouxe, portanto, uma proposta ampla em que foram inscritos 23 resumos; e, destes, selecionados 16 trabalhos completos para apresentação e debate - tendo comparecido, efetivamente, os autores de 12 contribuições. O público médio presente foi de 17 pessoas nos dois dias em que ele se realizou (10 e 11 de outubro de 2015). Foi composto em sua maioria por geógrafos - tanto por aqueles que desenvolvem pesquisa no âmbito da Geografia Física, quanto em Humana -, havendo ainda alguns filósofos de formação e pesquisadores provenientes de outros setores das ciências humanas.

Fizeram-se notar proposições de caráter teórico, de caráter metodológico; as influências de outras ciências na Geografia, assim como aquelas da Filosofia; debates epistemológicos, tanto com base nas proposições geográficas consolidadas, como calcados em matizes mais contemporâneos.

De vez que este texto pretende relatar as discussões havidas no GT, propomos aqui, na qualidade de seus coordenadores, uma síntese que procura prestigiar boa parte das discussões que vieram à tona. Agrupamos e as dividimos em três grupos: as que trataram da história do pensamento geográfico; as que trataram das influências filosóficas na Geografia; e, comentários daquelas que indicaram um interesse, sobretudo, pelo viés teórico-metodológico para executar estudos contemporâneos.

\section{EPISTEMOLOGIA E A HISTÓRIA DO PENSAMENTO GEOGRÁFICO}

A estreita relação entre as reflexões epistemológicas - sobre as condições, paradigmas, normatividade e limites do conhecimento - e a história do pensamento - sobre os contextos, fatos e encadeamentos históricos de postulados, correntes e autores - exigiu que destacássemos esta relação. É a terceira vez que no ENANPEGE se discerne os trabalhos de Epistemologia daqueles de História do Pensamento Geográfico (HPG). Mesmo que consideremos adequada a distinção dos GTs, nas três situações encontramos trabalhos que poderiam participar de ambos os grupos. Tal situação não necessariamente constitui um problema de discernimento, mas apenas expressa a estreita relação (já há muito percebida por outros estudiosos) entre a filosofia e a história das ciências.

Como lembra Claval (2006), é inerente ao desenvolvimento do pensamento geográfico expressar os contextos intelectuais, político-administrativos e econômicos dos diferentes 
períodos e territórios. Pode-se, então, encontrar em todos os trabalhos apresentados elementos que remetam à HPG. Contudo, para fins representativos, selecionamos os que mais requisitaram tal diálogo. Neste sentido, as considerações mais efetivas ocorreram basicamente em dois sentidos: um, apresentando os contextos históricos como dado, embasamento, legitimação de determinada leitura epistemológica sobre um autor, teoria, categoria, abordagem etc.; e outro, usando da história do pensamento para apresentar determinada ideia, autor, conceito (especificando, p.ex., sua formação e contextos), e empregar estes elementos na leitura de problemas, teóricos e práticos, contemporâneos.

No primeiro sentido citaríamos três trabalhos nos quais contextos históricos da Alemanha, Estados Unidos e Brasil foram requisitados para discutir as proposições, respectivamente, de Carl Ritter, Richard Hartshorne e Pierre Monbeig.

Ao pesquisar a obra "Geografia Comparada", de Carl Ritter, a pesquisa de Leitão (2015), “Apontamentos acerca da influência do Romantismo na obra Geografia comparada de Carl Ritter", remeteu as reflexões para o contexto europeu na transição entre os séculos XVIII e XIX. O período foi caracterizado por grande efervescência cultural, política e econômica. É o tempo de questionamento dos despotismos e racionalismos puros. Tanto na filosofia, quanto na política e economia, a palavra "revolução" é usada para descrever a situação. Trata-se do período da "Revolução copernicana" na filosofia, destacando-se o filósofo Immanuel Kant; da "Revolução Francesa" na política; e da "Revolução Industrial” na economia. Naquele período há o acirramento das disputas territoriais e a militarização de muitos países europeus. O conhecimento geográfico do mundo se expande de forma intensa e definitiva com as grandes explorações continentais - em busca de recursos naturais. Os conhecimentos e métodos das ciências não conseguem universalizar a multiplicidade encontrada. Neste momento, o Movimento Romântico buscou preservar a racionalidade, mas reclamava os limites da razão Iluminista. Destacava-se a necessidade de incluir a estética, o subjetivo, o emotivo, o nacional, o local, o efêmero, etc., nas discussões filosóficas e científicas. Por esses, a natureza é novamente concebida como orgânica e criativa.

Para o diálogo direto com o geográfico-empírico, os naturalistas tornam-se os protagonistas de releituras filosóficas e novas proposições metodológicas para lidar com a multiplicidade geográfica encontrada. A categoria forma - realçada em Kant - e o método comparativo - realçado na Linguística, Pedagogia e Economia - são requisitados para o estudo empírico da natureza. Há a necessidade de elaboração de metodologias para o estudo do fenômeno geográfico. A obra "Geografia Comparada", de Carl Ritter, surge neste complexo panorama, filosoficamente conjugando princípios racionalistas e românticos, e, contextualmente, num momento voltado tanto para a valorização dos traços nacionais - 
como- a cultura, a língua e a história -, quanto de militarização para proteção e expansão das fronteiras e afirmação de um Estado de Ordem.

A pesquisa teórico-metodológica desenvolvida por Arcassa (2015), “Concepção de método em Richard Hartshorne”, contextualiza-se no início do século XX, com as proposições de Richard Hartshorne. Este foi um período de grande incerteza nas diversas esferas: política, econômica, cultural e científica. O contexto histórico trazia tanto elementos de continuidades - por exemplo, o imperialismo -, quanto importantes questionamentos e rupturas em relação ao século XIX nas concepções político-econômicas do mundo e do conhecimento.

Em termos políticos, a Revolução Russa tinha demonstrado uma outra possibilidade para se alcançar o progresso Iluminista. Na economia, a década de 1930 foi considerada por muitos como uma das piores na história para o capitalismo. Nos Estados Unidos, Roosevelt implantava o New Deal, que previa, inclusive, planejamento espacial urbano, rural e industrial. Na cultura, temos a firmação e projeto de expansão da cultura de massa nos Estados Unidos e tensos embates políticos e xenófobos na Europa, com alianças e racismos convivendo em conflito. Os desacordos diplomáticos entre os países já encaminhavam a Europa para a Segunda Guerra Mundial. No conhecimento, a Ciência passava por importantes repercussões advindas da Teoria da Relatividade e Mecânica Quântica, tanto colocando incertezas e relativismos na dinâmica da realidade - o ontológico -, quanto inserindo incertezas e subjetividades no conhecimento dela - o epistemológico.

Neste contexto de questionamento, rupturas e tensões, Hartshorne dá um tom político e arbitrário para a região. A concepção de diferenciação de áreas referencia tal proposta. A pesquisa teórico-metodológica de Arcassa (2015) nos leva a perguntar: quais as influências deste contexto histórico nas proposições de Hartshorne? Já que a necessidade de se conhecerem as diferenciações espaciais havia sido destacada nas diversas esferas: militar, política, econômica e cultural?

A pesquisa de Rodrigues \& Godoy (2015) nos faz lembrar que, neste mesmo período da publicação do "The Nature of Geography" por Hartshorne, em 1939, no Brasil fazia dois anos que Pierre Monbeig publicara "As Zonas Pioneiras do Estado de São Paulo". Era o período hegemônico do Estado Novo. Depois da crise, a base econômica, que era preponderantemente pautada no café, foi sendo, aos poucos substituída pela indústria. A agricultura passou a desempenhar um papel não somente econômico, mas também de expansão territorial com fins administrativos de ocupação e funcionalização dos espaços. Num contexto de efetivação da divisão internacional do trabalho, as franjas pioneiras 
no oeste paulista e norte do Paraná desempenharam esse papel de ocupação e inserção de novas áreas no sistema econômico estadual-nacional-mundial. A intensa migração de italianos, japoneses, alemães, associados a áreas com relevos suaves, clima propício e latossolos férteis, que favoreceram a expansão.

Rodrigues \& Godoy (2015) discutem que a cosmovisão trazida por Pierre Monbeig concebia esse processo como civilizatório. Significava a superação do atrasado a partir de uma maior inserção do Estado de São Paulo, bem como do Brasil no projeto ocidental moderno. Muito expressava a ideologia progressista da época. As condições naturais, de um ambiente aparentemente hostil, representavam o território do atraso, o território intocado. O processo de modernização seria a reconstrução deste território trazendo o progresso técnico. Tais considerações nos instigaram, por exemplo, a perguntar: entendimentos biográficos seriam úteis para entender a cosmovisão do autor? Ou ainda, quais os problemas que a realidade das franjas pioneiras colocou para a abordagem vidalina trazida por Monbeig? Isso porque Monbeig não encontrou "regiões orgânicas" numa realidade tão dinâmica como era o oeste paulista e o norte paranaense - com a categoria território melhor se adequando; e, possivelmente, também tenha encontrado dificuldades para aplicar o conceito de "gênero de vida" no tratamento de imigrantes desenraizados e ainda sem vínculo "orgânico" com a terra.

No segundo sentido em que a história do pensamento foi requisitada nas discussões realizadas - para apresentar ideias, autores, conceitos originários de outros períodos e usá-los em leituras contemporâneas -, exemplificam-se três pesquisas: Ribeiro (2015), "Ensaio sobre $a$ arché geográfica soteropolitana”, sobre a noção de Arché, Alievi (2015), "Bacia hidrográfica enquanto entidade de análise na geografia da saúde: pressupostos teóricos em André Cholley", buscando pressupostos teóricos em André Cholley, e Carvalho (2015), "Filosofia, epistemologia e conteúdo biocivilizatório da Geografia”, com o conteúdo biocivilizatório.

As discussões epistemológicas trazidas por Ribeiro (2015) direcionaram a discussão para a Antiguidade pré-socrática, séculos V e VI a. C., em Mileto - área hoje pertencente à Turquia. Esse era um dos locais mais geograficamente estratégicos e dinâmicos do período, caracterizada por intensa atividade comercial. Neste período surge a noção de Arché, justamente para universalizar num princípio, fator, elemento único, a constância presente em todos os seres e entidades e em todos os momentos da existência; uma possível constância substancial frente à multiplicidade que se apresentava empiricamente em Mileto: de especiarias, de animais e vegetais, pessoas e culturas, além de histórias e relatos de lugares por viajantes. Para Tales a Arché seria a água; para Anaximandro o ar - ambos de Mileto -; para Xenófanes, a terra; e para Heráclito, o fogo. 
Tal conceito foi resgatado por Ribeiro (2015) para discutir uma possível Arché geográfica e como este princípio poderia auxiliar na compreensão da constituição dos lugares. O exemplo empírico foi o processo de formação da cidade de Salvador, na Bahia. Para Ribeiro (2015) no entendimento do mundo atual um dos principais elos de ligação entre a Arché filosófica e a geográfica é a técnica - em diálogo com as proposições de Santos (2008). E é essa técnica, que usada diferentemente nos lugares, ditaria a especificidade das transformações históricas geográficas, no caso, de Salvador. No diálogo destas propostas de contextos históricos diferentes, a questão que surge não é sobre a legitimidade de tal importação temporal e adequabilidade de sua aplicação, mas sim, se a "arché" é o "início", como compatibiliza-la com outras abordagens possíveis (p.ex., as biológicas) que tratam também, e com consistência teórica, de "origem"? Não haveria, algo anterior, mais profundamente enraizado na relação homem/meio que mais adequadamente poderia se chamar de arché geográfica?

Outro resgate de proposição foi feito por Alievi (2015). O autor resgata a "noção de combinaison em André Cholley, da década de 1960, para discutir o conceito de bacia hidrográfica com vista a usá-lo como entidade de análise para a Geografia da Saúde. A proposta de Cholley contextualiza-se na afirmação de uma abordagem analítica e uso da perspectiva sistêmica na disciplina. O período é caracterizado pela "idade de ouro dos países industrializados", pela Guerra Fria, pela planificação estatal, pela expansão das técnicas cibernéticas. A ciência passa a utilizar os modelos como meio de inquérito. As teorias sistêmicas são uma das principais a guiarem a elaboração e aplicação dos modelos nas ciências humanas; as técnicas estatísticas são as ferramentas operacionais. A Geografia busca se adequar ao período estudando os processos e organizações espaciais.

De acordo com Alievi (2015), a proposta de André Cholley busca destacar as organizações, descritas como combinações geográficas. "Além de sua própria estrutura e de sua essência, que devemos conhecer, é a combinação, na qual se reúnem, que lhes dá seu verdadeiro sentido" (Cholley, 1964, p. 139 apud Alievi, 2015, p. 5). A bacia hidrográfica associada à importação temporal dessa visão sistêmica e análise integrada pode, em sua concepção e método, ser tratada como conjugando aspectos naturais e antrópicos. Pode servir como ferramenta conceitual e analítica para os estudos da relação homem/meio e seus impactos na saúde humana.

Carvalho (2015) faz um apanhado histórico para argumentar sobre a construção de um modelo de civilização não-sustentável. Vem atentar para a necessidade de se pensar, em termos filosóficos e epistemológicos, um modelo biocivilizatório que inclua a vida como referência, e que faça frente ao modelo dependente de matrizes energéticas não- 
renováveis. A reflexão remete a discussão ao processo civilizatório europeu a partir do século XVI, quando a diversidade biogeográfica do mundo foi mais intensamente submetida ao processo civilizatório europeu. No século XIX esse projeto de apropriação abiótica, biológica e cultural do mundo se consolida, sendo requisitado nas diversas esferas: nas explorações continentais (em busca de recursos naturais para a indústria); na ciência (darwinismo, lamarckismo, etc.); na filosofia, com uma perspectiva criativa e orgânica de natureza; e na cultura, com as explicações biológico-eugênicas começando a ganhar força. Na política, este período coincide com a firmação dos Estados Nacionais e intensificação das disputas territoriais imperialistas - que culminariam na Primeira Guerra Mundial -, em muito para preservar e manter tais recursos em seus territórios.

Passados os extremos das Guerras Mundiais, em meados do século XX a nova ordem geopolítica estabelecida viabilizou o controle do que Foucault (1999 apud Carvalho 2015, p. 9780) se refere como a era do "biopoder". Tal modelo de apropriação da natureza pôde se expandir graças aos ordenamentos produzidos pelos Estados nacionais territorializados e legitimamente reconhecidos; ordenamento político-territorial que vem se configurando desde os séculos XVI e XVII. Uma proposta biocivilizatória vem, no contexto atual, destacar a necessidade de se conferir primazia à vida; a importância dos componentes espaciais e territoriais, incluindo a revisão das hierarquias promovidas pelo ordenamento geopolítico e também pelas divisões do trabalho com as consequentes especializações territoriais (e ambientais) que promovem.

Na relação entre epistemologia e história, tanto as questões epistemológicas compõem a história do pensamento geográfico, quanto os fatos históricos dão consistência às reflexões epistemológicas em Geografia. Contudo, a recente intensificação das discussões estritamente epistemológicas no âmbito da ciência geográfica em geral, destaca a jovialidade de tais reflexões. Como notou Monteiro (1980), a defasagem, em média, de cerca de 15 anos de incorporação dos entendimentos da Geografia Ocidental na Geografia brasileira, traz uma situação de ainda maior juventude e incipiência de tais discussões em âmbito nacional - passado o período de afirmação das perspectivas sistêmicas, críticas, humanísticas, etc. Com isso, muitas vezes percebe-se certas carências nas discussões. É comum, por exemplo, contextos históricos serem restritamente apresentados - o que limita o aprofundamento epistemológico -, e, muitas vezes, conceitos, abordagens, autores são requisitados para os problemas contemporâneos sem a contextualização histórica adequada das condições e intenções nas quais foram criados. Porém, mesmo observando tais situações, o problema não é específico da Geografia brasileira, nem mesmo específico da Geografia; mas estão presentes nas ciências em geral, mesmo as da natureza, cuja reanimação das discussões 
filosóficas e epistemológicas mais amplas ocorreram também mais intensamente apenas nas últimas décadas do século XX. As carências encontradas em âmbito nacional serão sanadas conforme o amadurecimento das proposições e discussões epistemológicas.

\section{AS INFLUÊNCIAS DA FILOSOFIA NAS PESQUISAS EM GEOGRAFIA}

Desde pelo menos os anos 1980 já se identificavam estudos de teor epistemológico no círculo de geógrafos brasileiros. Junto a universidades fluminenses e paulistas, pouco a pouco, pesquisas com tônus cada vez maior ganhariam visibilidade. Tomando a epistemologia em seu sentido mais dilatado - como a teoria do conhecimento de uma ciência - concluise que, de fato, estudos desse feitio, empreendidos por nossos pares, ganharam saliência sobretudo nas três últimas décadas - decurso de tempo que coincide, mais ou menos, com o amadurecimento e solidificação dos cursos de pós-graduação no Brasil.

Uma mirada no que registram atas de reuniões nos autoriza a dizer que os encontros que tiveram esse anseio de congregar pesquisadores atraídos pelo debate teórico em ciência geográfica - como, p.ex., o icônico Primeiro Encontro de História do Pensamento Geográfico, ocorrido na cidade paulista de Rio Claro, em 1999 - caracteristicamente sempre realçam as potenciais arestas de contato entre Filosofia e Geografia. E, muito embora as reuniões seguintes (nominadas colóquios ou simpósios) viessem a salientar o relevo dado às investigações de caráter principalmente historiográfico - com uma evidente preferência pelos estudos sobre personagens e instituições -, a reflexão filosófica não deixaria de estar presente; por mais que evidenciada por um simples exercício interpretativo dos pesquisadores - dispostos, às vezes, a demonstrar a filiação ideológica dos empreendimentos.

Nos gêneros de pesquisa que se aproximam mais explicitamente da Filosofia deixamse ver, no entanto, perspectivas bastante distintas. A questão é que se este fato pode, por um lado, realmente comprovar a fertilidade daquelas arestas de contato, por outro, dános indícios de que certos pesquisadores têm uma ideia simplista ou equivocada do campo da Filosofia da Ciência. Dizemos isso porque ainda acontece de alguns de nós chamarmos epistemológicos estudos que na verdade estão vinculados à ontologia. $\mathrm{E}$ a essa diferença quanto à natureza da investigação precisaríamos estar mais atentos. Os primeiros são, por excelência, estudos de segunda ordem. Devotam atenção às questões racionalidade, linguagem, julgamento e evolução das ideias e práticas científicas - por isso, aliás, a estreita relação entre epistemologia e metodologia. Os segundos são, por natureza, resplandecentemente conjecturais e meditativos; em especial, absorvidos por elucubrações em torno de temas, tais como a condição existencial dos sujeitos e dos entes; ou então 
por especulações sobre aspectos que estão bem “mais além" daquilo que basta às práticas rotineiras do cientista - por isso, então, o elo natural com a metafísica.

Bem, uma explicação alternativa para essa confusão pode residir no fato de termos, nos círculos intelectuais do país, uma indisfarçada afinidade com a chamada filosofia continental. Sendo assim, como se presume, tenderia a haver (como de fato uma avaliação bibliométrica logo nos evidenciaria) uma preferência por sistemas filosóficos associados a grandes nomes do pensamento alemão e francês - notadamente Nietzsche, Husserl e Heidegger; Sartre, Foucault e Derrida. Sistemas que, por constituírem escopo muito genérico, não são notáveis por se debruçarem especialmente sobre a prática concreta da ciência; e, por isso mesmo, não geraram modelos interpretativos robustos sobre ela - prática para a qual são essenciais, muito precisamente, nem mais nem menos do que aquelas quatro questões epistemológicas enumeradas no parágrafo anterior.

O mesmo fato, por conseguinte, redunda na condição de não ser frequente entre nós o recurso mais sistemático a outras "geografias" da Filosofia. No caso, estamos nos referindo à literatura filosófica de cepa anglo-americana. O estranho é que, não menos longeva e rica, ela possui exatamente o predicado de (a depender do autor, é claro) concentrar exclusivo esforço intelectual na análise filosófica das ações e dos produtos da ciência. Restringe-se, portanto, apenas ao microuniverso deste tipo de conhecimento. Falamos de autores tais como Nagel, Hanson, Toulmin, Hacking, van Fraassen, Giere, Sneed e Cartwright - para citar alguns nomes que contemplam o plural e largo espectro da Philosophy of Science pósCírculo de Viena.

Diríamos, então, que, a despeito da admirável heterogeneidade que as caracteriza, pairam sobre nossas pesquisas de teor teórico-reflexivo duas vertentes. Estas coincidiriam com duas modalidades pelas quais a Filosofia é explorada em estudos de epistemologia ou teoria do conhecimento geográfico. Uma, chamaríamos “Filosofia da Geografia” (F:G), inspirando especulações metafísico-ontológicas; outra, "Epistemologia da Geografia", mobilizando uma mirada do "caso" ciência geográfica pela lente peculiar/especializada da Filosofia da Ciência (FC:G).

Provavelmente ainda estejam predominando entre nós os estudos que se enquadram na primeira vertente. Mas gostaríamos de frisar que é o interesse por temas tais como a normatividade dos procedimentos - por exemplo, a concepção linguística dos modelos explanatórios - ou a evolução dos paradigmas - como o condicionamento conjuntural dos esquemas interpretativos - que realmente qualifica as pesquisas que merecem o adjetivo de “epistemológicas". E estamos convencidos de que se a segunda vertente passasse a ganhar 
uma atenção menos displicente, nós pesquisadores na área de Filosofia e Epistemologia da Geografia lograríamos ingressar com melhor desenvoltura no círculo de filósofos e historiadores da ciência - comunidade que já está adiantada no acompanhamento da literatura epistemológica, embora ainda desconheça nossos feitos jurisdicionais e pouco saiba das potencialidades filosóficas do caso Geografia.

\begin{tabular}{|c|c|c|}
\hline & F:G & FC:G \\
\hline Escopo & $\begin{array}{l}\text { Realidade das formas e dos } \\
\text { processos espaciais, em } \\
\text { seus aspectos essencial e } \\
\text { fenomênico. }\end{array}$ & $\begin{array}{l}\text { Alcance da teoria, } \\
\text { consciência do modelo e/ou } \\
\text { operacionalidade do conceito. }\end{array}$ \\
\hline \multirow{2}{*}{ Exemplo de Procedimentos } & $\begin{array}{l}\text { Definição dos preceitos } \\
\text { característicos dos sistemas } \\
\text { filosóficos, e identificação } \\
\text { dos mesmos na cosmovisão } \\
\text { veiculada pelos discursos. }\end{array}$ & $\begin{array}{l}\text { Avaliação do grau de } \\
\text { correspondência entre } \\
\text { a realidade e suas } \\
\text { representações científicas. }\end{array}$ \\
\hline & $\begin{array}{l}\text { Apreciação sobre os sentidos } \\
\text { dados às categorias ou } \\
\text { noções gerais do pensamento } \\
\text { geográfico. }\end{array}$ & $\begin{array}{l}\text { Argumentação e propósito } \\
\text { do contexto histórico } \\
\text { desencadeador das inspirações } \\
\text { teóricas e/ou das iniciativas de } \\
\text { aplicação empírica }\end{array}$ \\
\hline
\end{tabular}

\section{PROPOSIÇÕES TEÓRICO-METODOLÓGICAS EM GEOGRAFIA PARA OS ESTUDOS CONTEMPORÂNEOS}

Indicar um grupo de trabalho em que se verifiquem proposições do tipo teóricometodológicas para os estudos geográficos pareceria "chover no molhado". Isso porque já se pressupõe que, num encontro da envergadura do ENANPEGE, parte expressiva dos trabalhos inscritos, em seus diferentes GTs, possuam essa característica. Por isso, frisamos aqui especialmente a "contemporaneidade", como um dos elementos centrais do debate, quando os pesquisadores - a partir de teorias, categorias e conceitos consolidados na Geografia - vão aferir a pertinência teórico-metodológica de suas proposições. Tratamos de, em parte, relevar - principalmente, por meio de descrições - o esforço de alguns autores do GT em discutir a "Epistemologia da Geografia", por meio de argumentações que relacionaram certa realidade e a representação científica. De toda maneira, isso não significa que as discussões atinentes à "Filosofia da Geografia" não estejam presentes.

De modo geral, as proposições vieram com forte apelo teórico - o que oportunizou debates intensos; principalmente pelo fato de seus autores exporem e abrirem à discussão suas respectivas trajetórias investigativas e conclusões provisórias decorrentes. 
Determinados trabalhos possuíam maior sintonia uns com os outros. Por exemplo, os de Miranda et al. (2015), "Algumas reflexões da paisagem nas abordagens culturais em Geografia", Santana (2015), "O espaço e o sujeito em sociedade: totalidades da totalidade", e Nabozny (2015), "Ordenamento espacial moderno e conhecimentos situados". Estes três trabalhos se aproximam, em certa medida, pelo debate acerca de questões atinentes ao conceito de sujeito, numa correlação aparente com algumas das categorias tradicionais da ciência geográfica.

Miranda et al. (2015) parte do exame de diferentes concepções de paisagem nos estudos geográficos e atribui ênfase àqueles vinculados à abordagem da chamada Geografia Cultural de corte "humanista". O sujeito comparece no debate como aquele que vivencia o mundo, e a paisagem está em relação com ele. O elo entre paisagem e cultura resulta no que os autores denominam paisagem cultural - sendo que ela possibilitaria o exame tanto das territorialidades, como das temporalidades. Daí ser possível identificar e entender os “símbolos", as “memórias”, as “identidades”, as “imagens”. Segundo os autores:

A paisagem vista através dos olhares de sujeitos, remonta a memória e vivência, e, isto influenciará nos sentimentos e comportamentos dos indivíduos em relação à própria, (re) criando-a e transformando-a. (Miranda et al., 2015, p. 9857).

Santana (2015), por sua vez, parte das diferentes concepções de ator e agente, indicando que cada qual possui distintas matrizes de abordagem para o sujeito. A partir de sua constatação aborda a totalidade segundo proposições atribuídas a Lefebvre (1955), Kozik (1976) e Santos (2006), para as quais as "múltiplas totalidades" se relacionam dialeticamente: um mesmo movimento, compreendendo vários ritmos. Nesse sentido, o autor almejou desenvolver

[...] a discussão teórico-metodológica acerca da relação entre o sujeito, o espaço e a sociedade. Especificamente diz respeito a mútua imbricação entre o sujeito e o espaço em sociedade. [...] Nesse sentido, pensar o espaço significa simultaneamente pensar a sociedade e o sujeito no intuito de repensar suas existências de forma relacional e crítica. (Santana, 2015, p. 9786).

O sujeito advém aqui numa relação contraditória com o espaço, em que as totalidades são diferentes níveis de entendimento do real. Para o autor, a discussão proposta vem a ser uma conscientização "em torno dos papéis cruciais que o sujeito e o espaço possuem e assumem no bojo da sociedade, principalmente no intento de transformá-la" (Santana, 2015, p. 9786).

Já Nabozny (2015) estuda os moradores de áreas de habitação irregular, as famílias realocadas pelo Estado, e problematiza suas trajetórias de vida, enfatizando as relações intersubjetivas e suas apreensões da produção social do espaço urbano, na cidade de Ponta 
Grossa, Estado do Paraná. Destaca-se o conceito de "lugaridade”, como proposto por Relph (2012), e o desenvolvimento de metodologias de pesquisa qualitativa para a interpretação e entendimento do real.

Ao mesmo tempo em que os sujeitos sociais e suas espacialidades são compreendidos pelo ordenamento espacial moderno, visa-se também, por meio das experiências espaciais dos sujeitos, expandir o ideal de racionalidade e seus efeitos sociais situados. Ressalta-se, por fim, a discussão da produção do espaço geográfico e suas múltiplas valorizações, como perspectiva de discussão de uma história social da Geografia do tempo presente, na inter-relação de saberes e suas respectivas implicações em termos das demarcações teórico-metodológicas. (Nabozny, 2015, p. 9813).

Os sujeitos comparecem na discussão proposta por Nabozny, sejam eles os pesquisadores ou os pesquisados, como produtores de centros relativos de espacialidade. Para isso há o desenvolvimento de uma metodologia de pesquisa dialógica, a fim de interpretar o meio de existência e a lugaridade dos moradores.

Pode-se aferir pelos excertos que não necessariamente o conceito de sujeito é aquele que norteou as comunicações; entretanto, por ele, se pode delinear uma proximidade entre as falas e suas respectivas abordagens teórico-metodológicas. O trabalho de Nabozny parte de uma preocupação fundamentada na identidade e na lugaridade de sujeitos ponta-grossenses que são moradores de áreas de habitação irregular, e destaca o aspecto metodológico da pesquisa que, segundo ele, se justifica para tratar do sujeito em estudos geográficos. Miranda et al. e Santana partem de pressupostos teóricos em consonância com conceitos e categorias tradicionais da Geografia, a fim de discutir os fenômenos contemporâneos em que se consideram os sujeitos.

Ainda que possível de identificar no quadrante das propostas teórico-metodológicas, o trabalho de Ribeiro (2015), destoa dos três anteriores; mas ele o fundamenta, assim como Nabozny (2015), no espaço e nas dinâmicas urbanas contemporâneas. Como vimos antes, Ribeiro propõe a arché como um "princípio" - presente, em todos os momentos da existência dos entes -, mirando a conceituação de uma "arché geográfica", a qual estaria na origem do espaço e permanecendo nele.

[...] a cidade de Salvador da Bahia possui peculiaridades interessantes que enriquecem as possibilidades do pensamento sobre o conceito em foco. Testemunha do início do processo de mundialização, sendo desde sua origem centro regional enquanto periferia mundial, portadora de uma história forte e uma geografia fascinante, a primeira capital do Brasil é uma fonte riquíssima para reflexões, incluindo sobre sua arché espacial. (Ribeiro, 2015, p. 9833).

O espaço geográfico para o autor é um arranjo entre "essência" - a arché ou, espaço geográfico "des-coberto" -, o mundo e a paisagem. Ribeiro indica que a compreensão da arché espacial está fundamentada na concepção de Santos (2007) para o espaço geográfico, 
sob as categorias estrutura, processo, função e forma. Nesse sentido, ele não só propõe um conceito para abordagem espacial nos estudos geográficos - notadamente, para a realidade soteropolitana -, mas também o faz por meio de diálogos com teorias geográficas consolidadas.

Outro autor se utilizou da proposição de Santos (1985), em que, para o entendimento da realidade, o espaço geográfico é entendido pelas categorias estrutura, processo, função e forma. Trata-se de Borges (2015), em “Forma, processo, estrutura e função como categorias do método geográfico, aplicadas à identificação de centralidades intraurbanas”.

[...] ressaltando os processos atuantes na constituição desse fenômeno, as formas espaciais estabelecidas a partir desses processos, e a estruturas (re)produzidas na (re)definição das funções espaciais. Tais levantamentos resultaram na compreensão das distintas centralidades intraurbanas e contribuíram no entendimento dos processos, das formas, das funções e das estruturas atuantes e produzidas nestas áreas que se apresentam como sendo os principais pontos conversores/dispersores dos fluxos e fixos do capital no espaço intraurbano. (Borges, 2015, p. 9726).

Pode-se considerar que os trabalhos de Nabozny, Ribeiro e Borges possuem como fundamento empírico de suas proposições o espaço urbano e as respectivas dinâmicas sociais. Enquanto Nabozny (2015) parte da urbanidade e propõe o estudo dos sujeitos, suas identidades e lugaridades, destacando os procedimentos metodológicos da pesquisa, Ribeiro (2015) e Borges (2015), a partir do entendimento e crítica de teorias consolidadas, propõem novas aplicações nos estudos geográficos de urbanos.

Alievi (2015) segue um pouco a mesma perspectiva de Ribeiro e Borges: se vale de uma noção consolidada na Geografia, para aplicações contemporâneas. A pesquisa, ainda em andamento, não terá, todavia, a cidade ou o espaço urbano como objeto; e sim a unidade sistêmica bacia hidrográfica, direcionada para um estudo em Geografia da Saúde.

No âmbito da Geografia da Saúde, procura-se neste ensaio advogar em favor da utilização da bacia geográfica enquanto recorte espacial e analítico, partindo-se da metodologia de análise geográfica promovida por Andre Cholley em sua teoria das Combinações Geográficas. Parte-se do pressuposto que a mesma é a concreticidade de uma determinada combinação geográfica - um arranjo espacial e analítico caracterizado pela relação interdependente dos elementos ambientais e humanos em uma determinada área. (Alievi, 2015, p. 9824).

Alievi (2015), a partir da ideia de “combinações geográficas", desenvolvida por Cholley (1942; 1964), sustenta ser a bacia hidrográfica um recorte espacial próprio para os estudos sobre meio ambiente e saúde. A considera como um "todo", em que se verificam relações entre processos, estruturas e formas; relações essas que são de interdependência - tanto nos aspectos humanos, quanto nos físicos -, e que devem, por isso, merecer uma abordagem do tipo sistêmica. 
Por fim, destaca-se o trabalho de Carvalho (2015). Consideramos que, de certo modo, o autor segue o mesmo gênero de linha propositiva identificada em Alievi, Ribeiro e Borges: baseia-se num determinado referencial teórico-metodológico consolidado na Geografia e pretende o desenvolvimento de uma proposta de interpretação e entendimento de fenômenos contemporâneos. Nas palavras do pesquisador:

Referimo-nos às possibilidades de examinarmos as conexões entre a proposta de uma biogeografia universal sugerida por F. Ratzel, com aquelas de biocivilização de Ignacy Sachs (inspiradas nas ideias de civilização do vegetal de Pierre Gourou), como possíveis antídotos a era de biopoder que vivenciamos há alguns séculos, conforme a caracterizou Michel Foucault. (Carvalho, 2015, p. 9774).

O autor critica e propõe meios de superação de alguns antagonismos tradicionais, tais como aquele entre ciência e filosofia. Baseando-se nas discussões realizadas por Santos (2006) e Virilio (1984), acerca das técnicas, afirma que a Geografia possui os meios para superar as "disjunções e reduções a que fomos conduzidos por saberes desconectados" (Carvalho, p. 9775), em uma "situação de reconhecida crise socioambiental e cognitiva" na contemporaneidade (Carvalho, p. 9775).

Consideramos que uma vez ressaltadas essas discussões que tiveram como elemento aglutinador uma determinada proposição teórico-metodológica, é possível sacar um ou mais pontos em que elas se aproximam - em discurso, teoria ou método. De modo geral, poderíamos afirmar que os autores partem de pressupostos consolidados na Geografia e intentam constituir contribuições teóricas para estudos contemporâneos. Há, no entanto, diferenças entre as propostas - como se pôde notar na breve descrição de cada um dos trabalhos referidos acima.

Os trabalhos de Nabozny (2015), Ribeiro (2015) e Borges (2015) possuem como fundamento concreto de suas proposições as dinâmicas sociais atinentes ao espaço urbano. Isso indica que cada um dos autores buscou não só discuti-las teoricamente, mas buscar referencia-las empiricamente. Os trabalhos de Miranda et al. (2015), Santana (2015), Carvalho (2015), Alievi (2015), Ribeiro (2015) e Borges (2015) partilham a característica de constituir estudos de cepa teórica. Complementarmente, na pesquisa de Nabozny (2015) há certo realce quanto à metodologia de investigação - qualitativa, no caso. Nas comunicações de Nabozny, Miranda et al. e Santana houve, em maior ou menor grau, relevo à questão "sujeito" na Geografia; tomada para viabilizar o estudo de fenômenos contemporâneos. Por fim, os trabalhos de Carvalho, Alievi, Ribeiro e Borges possuem como timbre não apenas um debate teórico-metodológico, mas inclusive uma proposição teórica claramente articulada com certos pressupostos consolidados na disciplina. 


\section{CONSIDERAÇÕES}

As considerações se pautam em dois predicativos. A avaliação do GT realizada pelos participantes e aquela que é dos próprios autores deste artigo, na qualidade de condutores das duas sessões do GT.

Os autores apresentadores de trabalhos foram estimulados a avaliar o encontro no dia 11 de outubro de 2015, ao final da segunda e última sessão de debates. Por um lado, destacaram as problematizações - ricas e oportunas - recebidas/emitidas no decorrer do GT. Privilegiando as discussões, terminou sendo possível haver uma boa troca de experiências - viabilizada, ademais, pela apreciável quantidade de trabalhos aprovados e pela dinâmica instituída para a condução do GT. Outro ponto sublinhado foi a participação de pesquisadores de outras áreas e o decorrente benefício da interlocução que disso surtiu: posicionamentos ativos, com sugestões e críticas. Além disso, houve também manifestações a favor de um aprimoramento dessas reuniões entre pesquisadores interessados em Filosofia e Epistemologia. Por exemplo, no sentido de, talvez, proceder a um rearranjo dos GTs de modo a, quem sabe, favorecer a maior confluência de trabalhos que, apesar de terem estado inseridos em outros GTs, a bem dizer possuem a espinha dorsal comum de serem estudos teóricos e/ou conceituais. Um GT mais ecumênico poderia ensejar a criação de uma rede entre os jovens pesquisadores brasileiros; estimulando, decerto, a continuidade frutuosa dos debates e intercâmbios.

Quanto à nossa atuação enquanto condutores do GT, cabe mencionar que registramos todos os apontamentos feitos pelos participantes, considerando-os pertinentes e merecedores de uma documentação a ser recuperada pelos próximos responsáveis. Além disso, incentivamos os presentes a conservarem entre si um contato acadêmico, por meio de correios eletrônicos e redes sociais.

No primeiro tópico foi discutido, com base nos trabalhos apresentados no GT, a relação entre a Epistemologia da Geografia e a História do Pensamento Geográfico. Privilegiamos os debates que acerca dos contextos históricos de determinada leitura epistemológica (seja atribuída a um autor; seja associada a uma noção teórica). Por outro lado, quisemos também realçar os trabalhos que, a partir da História do Pensamento Geográfico, seus autores apresentam determinados pressupostos para usá-los na leitura de problemas, teóricos e práticos, contemporâneos. No segundo tópico, indicamos alguns dos fundamentos dessas discussões, destacadamente as diferenças e predominâncias nas pesquisas inscritas na "Epistemologia da Geografia" (FC:G) e na "Filosofia da Geografia” (F:G). No último tópico, prestigiamos as respectivas contribuições e assertivas dos autores e apresentadores do 
GT. Agrupamos os trabalhos por consequência da dedução aproximada de um ou alguns parâmetros em comum. Pela descrição realizada, podemos notar que perpassam a todos eles, cada um em maior ou em menor intensidade, discussões de algum modo pertinentes à Epistemologia e à Filosofia.

Por fim, há de se considerar que esse manuscrito é não mais que uma breve descrição, que constitui apenas um quadro mostruário do gênero de pesquisas que, aparentemente, têm sido executadas junto aos Programas de Pós-Graduação brasileiros.

FIGURA 2 - PRIMEIRA SESSÃO DE APRESENTAÇÕES E DEBATES (10/10/2015)

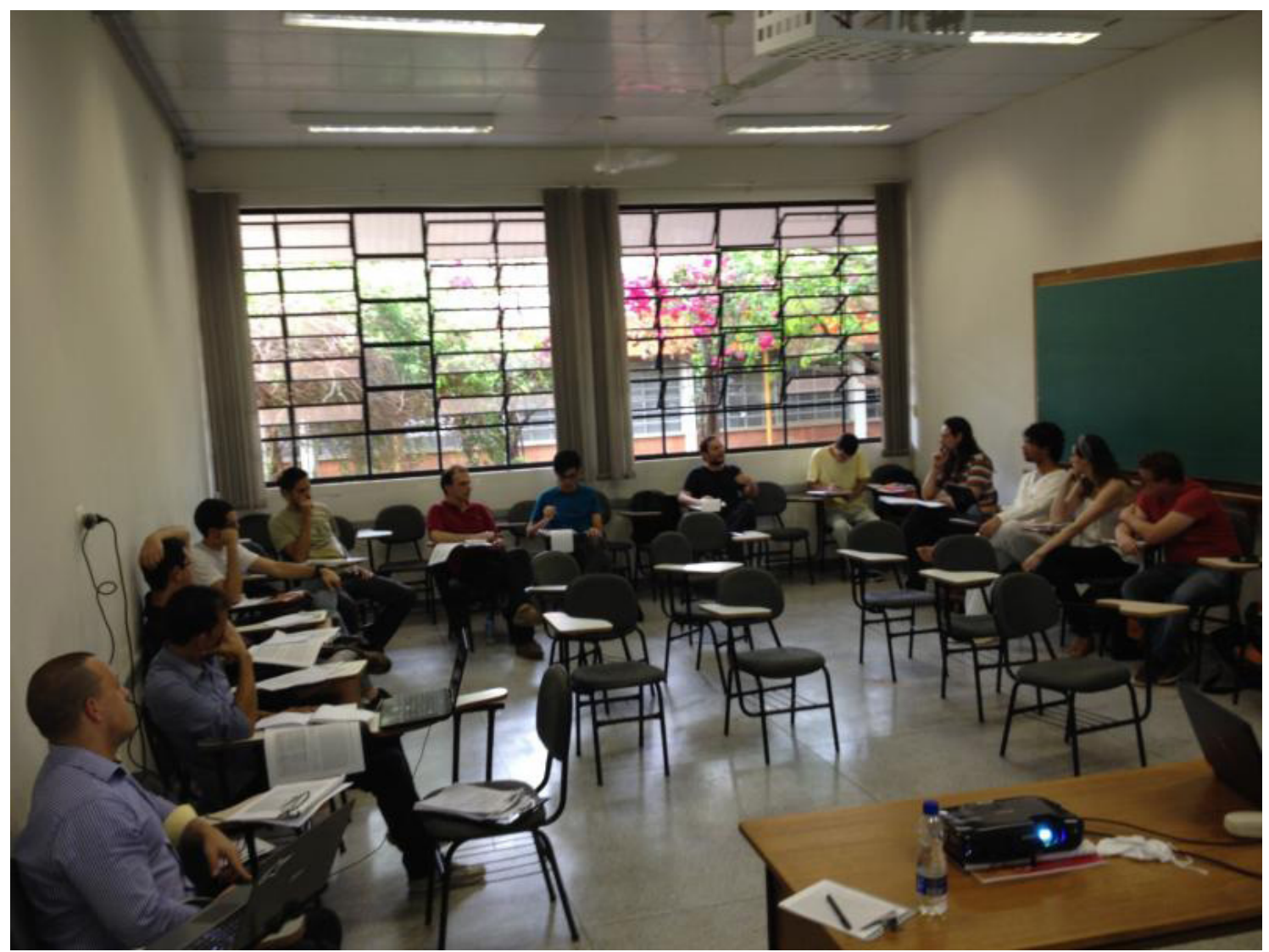

Foto: Dante Reis Jr. 
FIGURA 3 - ENCERRAMENTO DO GT (11/10/2015)

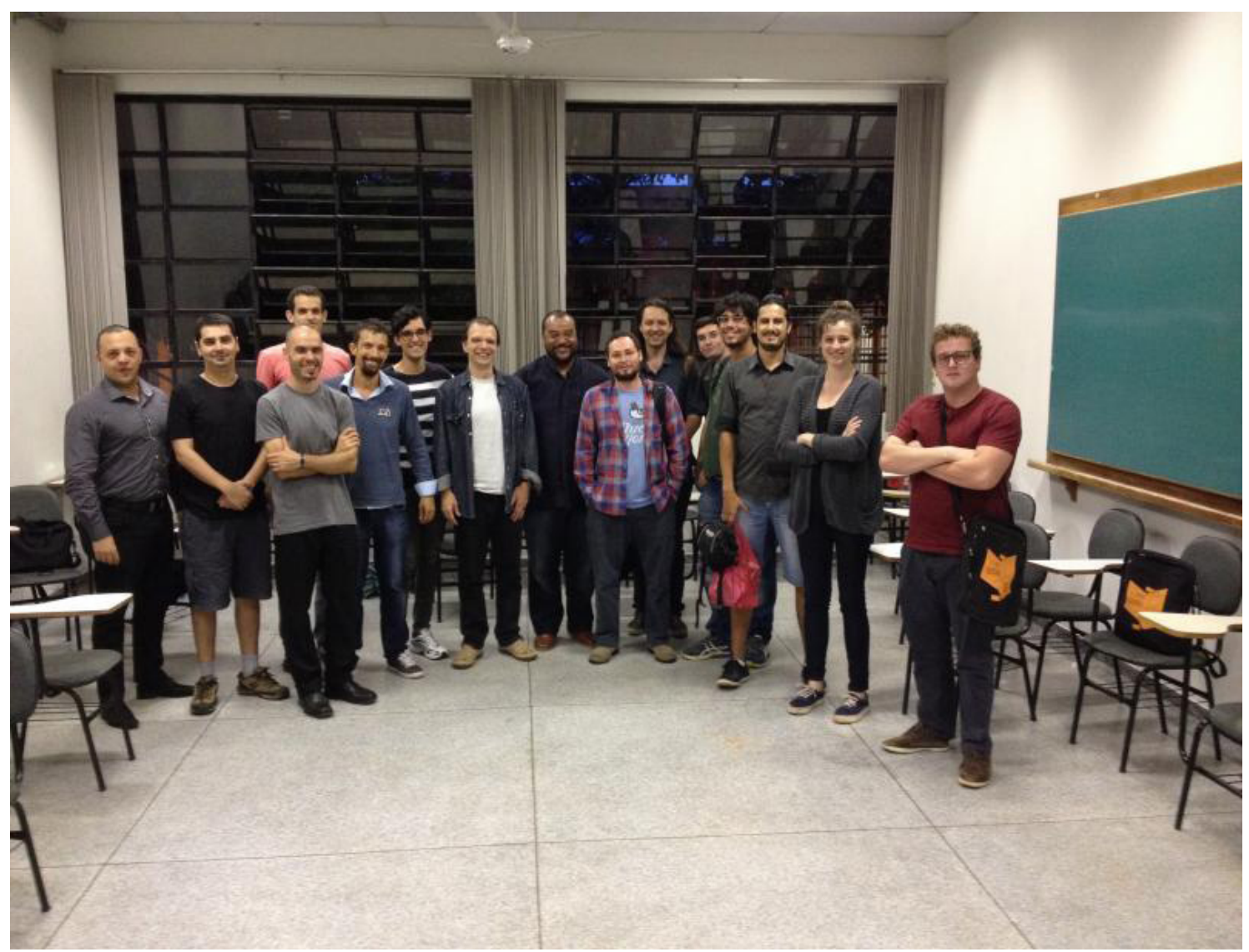

Foto: Dante Reis Jr.

\section{REFERÊNCIAS}

1. ALIEVI, Alan A. Bacia hidrográfica enquanto entidade de análise na geografia da saúde: pressupostos teóricos em André Cholley. In: Encontro Nacional da ANPEGE, 11., 2015, Presidente Prudente. Anais... Presidente Prudente: UNESP-FCT, 2015, p. 9824-9832.

2. ARCASSA, Wesley de Souza. A concepção de método em Richard Hartshorne. In: Encontro Nacional da ANPEGE, 11., 2015, Presidente Prudente. Anais... Presidente Prudente: UNESPFCT, 2015, p .9762-9773.

3. BORGES, Rhafael da C. Forma, processo, estrutura e função como categorias do método geográfico, aplicadas à identificação de centralidades intraurbanas. In: Encontro Nacional da ANPEGE, 11., 2015, Presidente Prudente. Anais... Presidente Prudente: UNESP-FCT, 2015, p. 9726-9737.

4. CARVALHO, Marcos B. de. Filosofia, epistemologia e conteúdo biocivilizatório da Geografia. In: Encontro Nacional da ANPEGE, 11., 2015, Presidente Prudente. Anais... Presidente Prudente: UNESP-FCT, 2015, p. 9774-9785. 
5. CHOLLEY, André. Guide de l'étudiant en géographie. Paris: PUF, 1942.

6. CHOLLEY, André. Observações sobre alguns pontos de vista geográficos. Boletim Geográfico, Rio de Janeiro, v. 22, n. 179, p. 139-145, 1964.

7. CLAVAL, Paul. História da Geografia, Edições 70, 2006.

8. KJELLÉN, Rudolf. Grundrisse zu einem System der Politik. Leipzig: Hirzel Verlag, 1920. Disponível em: <https://archive.org/search.php?query=kjellen>. Acesso em: 08 jan. 2016.

9. KOSIK, Karel. Dialética do concreto. Rio de Janeiro: Paz e Terra, 1976.

10. LEFEBVRE, Henri. La notion de totalité dans les sciences sociales. Cahiers Internationaux de Sociologie, Paris, v. 18, p. 55-77, 1955.

11. LEITÃO, Jóyce Oliveira. Apontamentos acerca da Influência do Romantismo na obra Geografia Comparada de Carl Ritter. In: Encontro Nacional da ANPEGE, 11., 2015, Presidente Prudente. Anais... Presidente Prudente: UNESP-FCT, 2015, 9899-9906.

12. MIRANDA, Everton; NABOZNY, Almir; SOUZA, Edson B. C. de. Algumas reflexões da paisagem nas abordagens culturais em Geografia. In: Encontro Nacional da ANPEGE, 11. 2015, Presidente Prudente. Anais... Presidente Prudente: UNESP-FCT, 2015, p. 9857-9867.

13. MONTEIRO, C. A. F. A Geografia no Brasil (1934-1977): avaliação e tendências. São Paulo, USP, Instituto de Geografia, 1980, 155p.

14. NABOZNY, Almir. Ordenamento espacial moderno e conhecimentos situados. In: Encontro Nacional da ANPEGE, 11., 2015, Presidente Prudente. Anais... Presidente Prudente: UNESPFCT, 2015, p. 9813- 9823.

15. REIS JR., Dante F. C. Universais de filosofia, história e geografia das ciências ... e o exemplar fértil da ciência geográfica. In: Seminário Nacional de História da Ciência e da Tecnologia, 14., 2014, Belo Horizonte. Anais... Belo Horizonte: UFMG, 2014. $15 f$.

16. RELPH, E. Reflexões sobre a emergência, aspectos e essência de lugar. In: MARANDOLA JR., Eduardo; HOLZER, Werther; OLIVEIRA, Lívia de (Org.). Qual o espaço do lugar? São Paulo: Perspectiva, 2012. p. 17-32.

17. RIBEIRO, Daniel de A. Ensaio sobre a arché geográfica soteropolitana. In: Encontro Nacional da ANPEGE, 11., 2015, Presidente Prudente. Anais... Presidente Prudente: UNESP-FCT, 2015, p. 9833-9867.

18. RODRIGUES, Guilherme Caruso, GODOY, Paulo Roberto Teixeira de. Ocupação das Franjas Pioneiras como pauta da Modernização: debatendo o Pensamento de Pierre Monbeig. In: Encontro Nacional da ANPEGE, 11., 2015, Presidente Prudente. Anais... Presidente Prudente: UNESP-FCT, 2015, p.9798-9812.

19. SANTANA, João P. M. de. O espaço e o sujeito em sociedade: totalidades da Totalidade. In: Encontro Nacional da ANPEGE, 11., 2015, Presidente Prudente. Anais... Presidente Prudente: UNESP-FCT, 2015, p. 9786- 9797.

20. SANTOS, Milton. Espaço e método. São Paulo: Nobel, 1985. 
21. SANTOS, Milton. A natureza do espaço: técnica e tempo, razão e emoção. São Paulo: EDUSP, 2006.

22. SANTOS, Milton. Metamorfoses do espaço habitado: fundamentos teóricos e metodológicos da Geografia. São Paulo: EDUSP, 2007.

23. VIRILIO, Paul; LOTRINGER, S. Guerra pura: a militarização do cotidiano. São Paulo: Brasiliense, 1984.

Artigo recebido em 23 de fevereiro de 2016.

Artigo aceito em 23 de março de 2016. 